\title{
Interaction Analysis of a Biology Chat
}

\author{
Gerry Stahl
}

\begin{abstract}
This is an analysis of data from a first attempt to combine (a) VMT technology, (b) helping agents, (c) collaborative small groups, and (d) accountable-talk prompting in order to scaffold biology student online chats about videotaped results of a biology experiment. Analysis of the response structure of the chat log of one of the student groups reveals characteristics of their interactions in terms of building collaborative knowledge. In particular, the mediation by the VMT technology, helping agents and accountable-talk training is analyzed to determine their influences in promoting productive learning-oriented interaction. A design-based research analytic perspective provides suggestions for redesign of the socio-technical approach based on the findings of the interaction analysis.
\end{abstract}

This chapter takes a specific analytic approach, developed within the Virtual Math Teams (VMT) Project (Stahl, 2009). The VMT research team adapted video-based interaction analysis of face-to-face discourse (Jordan \& Henderson, 1995) to analyze synchronous text chat by students in their mid-teens as they interact in the online VMT environment, discussing issues raised in school mathematics. From a structural viewpoint, the most important aspect of discourse is its temporal sequentiality; the field of Conversation Analysis has analyzed this extensively, beginning with (Sacks, 1962/1995) and summarized more recently by (Schegloff, 2007). We adapted such sequential analysis to student chat discourse in the VMT environment at the foundational level of "adjacency pairs" of mutually responsive postings (Stahl, 2006) and at the "longer sequence" level (Stahl, 2011a), which is the key level for knowledge building in computer-supported collaborative learning (CSCL).

In this chapter, I apply the method we developed in the VMT Project to a chat among three students discussing a biology experiment conducted in an early version of the environment formally known as ConcertChat (now VMT). The text chat was integrated with class discussion, a worksheet and videos. In addition, the software was extended with a software agent, which interacted with the students as a chat participant. I ignore most of the larger context of the experiment in membrane permeability (see chapter by Gregory Dyke, Iris K. Howley, Rohit Kumar, \& Carolyn P. Rosé in this volume) and focus on what is visible in the chat log (see Appendix).

\section{Method}

1. I was supplied with the logs of 16 chats, in spreadsheet format. The chats each lasted about a half an hour and contained the chat postings of three students and an agent. The 16 chats were divided among three conditions: in one condition the agent prompted students (indirectly) to ask each other to make specific accountable-talk moves; in a second condition the agent prompted students (directly) to make specific accountable-talk moves; in the final condition the agent did not make any accountable-talk prompts, but only guided the students through the steps of the assignment (as was also done in the first two conditions).

2. I read through each of the 16 chat $\operatorname{logs}$ that I was given and I wrote down a couple sentences of my initial reaction to the quality of the interaction. It seemed to me that similar patterns of interaction were arising in the $16 \mathrm{logs}$, and so I decided to analyze one chat in detail to get at key common patterns. I selected $\log \mathrm{C} 01$ as representative and promising for illustrating the common patterns. This 
case was from the first condition, in which the agent gave indirect prompts. Clearly, other analyses with different research questions and approaches would want to contrast the different conditions (e.g., Goggins, this volume), but from my focus on response structure it seemed particularly useful to look closely at one typical example.

3. In order to make the interaction flow visible, I rearranged the spreadsheet to have the postings of each participant in its own column (see the Appendix). The newer version of VMT produces logs in this format automatically for students, teachers and analysts. We often also have columns for time elapsed since the previous posting and time when a posting was starting to be typed. These figures sometimes help to determine which previous posting a new posting is responding to. In the current log, such detailed reasoning was not generally necessary.

4. I next sketched the response structure of the chat (see Figure 1). I drew an arrow from each posting to the prior posting to which it was responding interactively, for instance to what question is an answer responding? This already gave a visual impression of some aspects of the patterns of responses. These patterns are central to the interactional dynamic of the group.

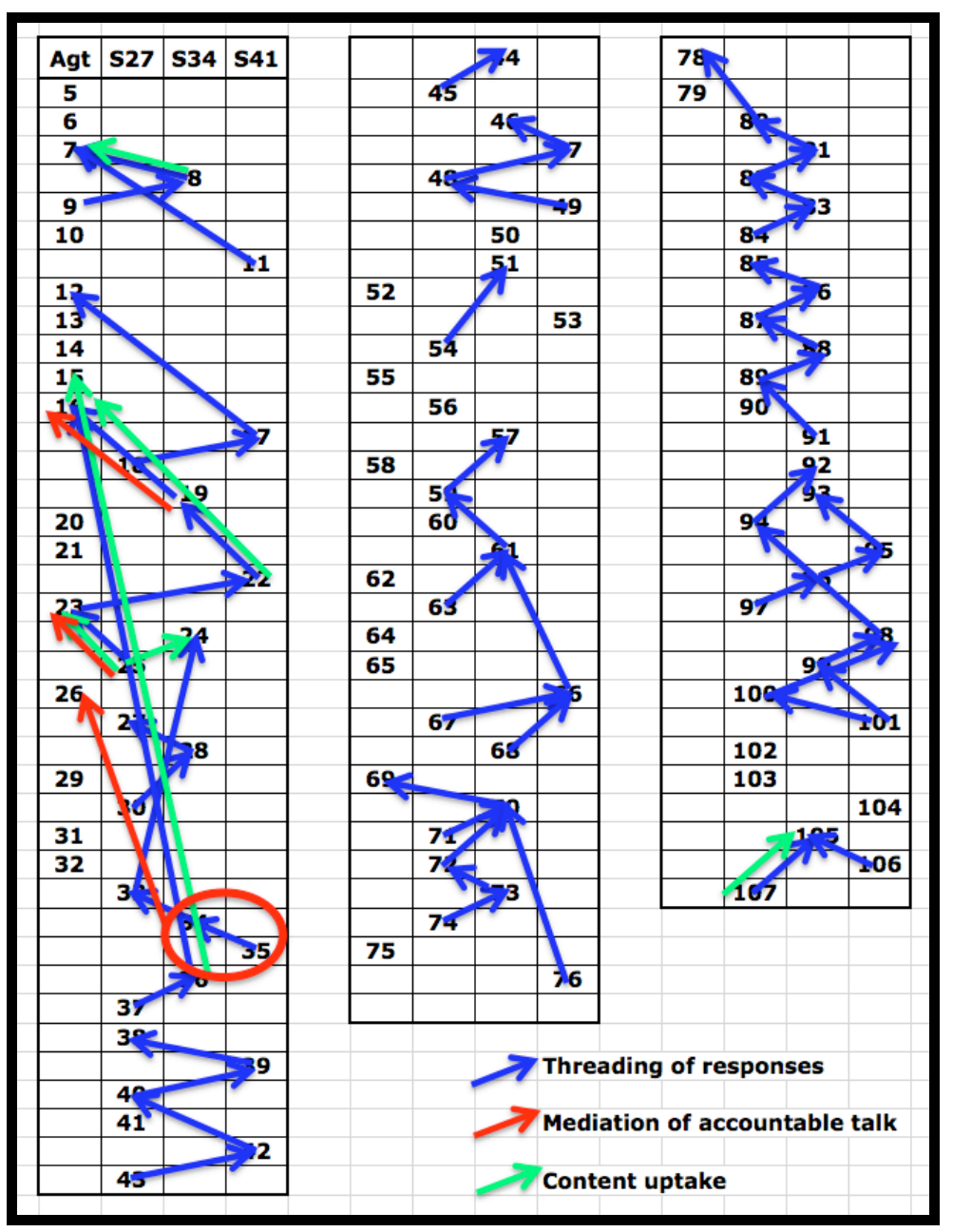

Figure 1. Sequential response structure of chat C01. Note that only interactions between actors are represented, not instances of a posting by one actor building on his, her or its own previous posting.

5. An important phase of interaction analysis is the exploration of the data, line-by-line, in a data session with other researchers (Jordan \& Henderson, 1995). This inherently dialogical or multi-vocal 
approach can bring in multidisciplinary perspectives and balance one-sided views. A data session can be most effective once some initial analysis has already been undertaken by one of the researchers. After the data session, suggestions have to be synthesized and followed up with further detailed data analysis. There can be multiple cycles of group and individual analysis. The data session for this chapter's analysis included experienced online educators from the Math Forum and two analysts from other chapters (Rosé and Goggins). The session suggested a more complex representation of the response structure, it refined interpretive details, and it situated the case study in a deeper understanding of the experimental context. In particular, the data-session discussion produced the representation of response structure of accountable talk (Resnick, O'Connor \& Michaels, 2007) shown in Figure 2, which was used in refining Figure 1.

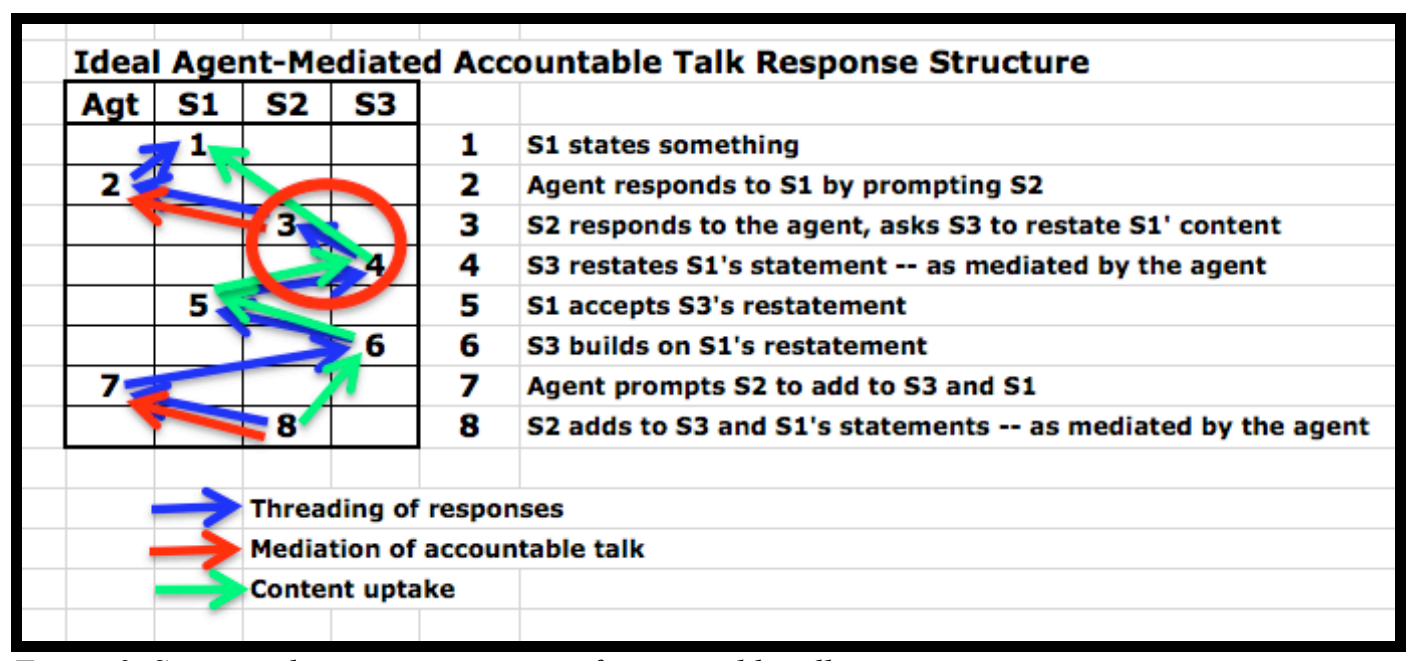

Figure 2. Sequential response structure of accountable talk.

6. Once I had a preliminary view of the response structure of the discourse in the chat, I could start to formulate tentative observations about the case study. These observations led to looking at the textual content of the postings. This showed the nature of the group interaction in more detail. The evolving analysis (see next section) also revealed the understandings and reactions of the students to their situation. This highlighted the response of the student group to its given task and to the actions of the agent, to the accountable-talk training and to the software environment.

7. As I summarized my observations (see discussion section), I felt that they generally applied to the other chats as well. By grouping the problems in relation to different design decisions in the experiment, I was able to propose several general suggestions for future re-design (see final section). Other analysts, taking into account other data, additional knowledge of the constraints on the experiment, and alternative research questions will undoubtedly reach different-hopefully complementary - conclusions. I was interested in seeing what insights an interaction analysis of a single case study could provide for the long-term design-based-research effort. I wanted to do this analysis strictly on the basis of the chat data from a single case study, without being concerned about the many constraints, practicalities, and concerns that influenced the experimental design in all its complexity.

\section{Analysis of the Chat-Response Structure}

Figure 2 shows a representation of the response structure of an ideal accountable-talk interaction, as hypothesized by the experiment. The blue arrows indicate that the agent responds to the students (line 2 and 7) and that the students in turn respond to the agent (lines 3 and 8). There is also a sequence in which 
the students respond to each other (lines $3,4,5,6$ ). This produces a tight group interaction including the agent and the students. The green arrows indicate that subsequent postings often involve uptake of content from previous postings (e.g., lines 4, 5, 6, 8 by the students). The role of the agent does not involve content, but mediates the student uptake of content by means of accountable-talk prompts (lines 2 and 7 , pointed to by the red arrows). Let us see the extent to which the data of actual interaction among students and the agent includes similar patterns of response.

Figure 1 indicates three instances of mediation of accountable talk (red arrows): (i) the response at line 19 to line 16, (ii) the response at line 25 to line 23, and (iii) the response at lines 34 and 35 to line 26 . Let us consider each of these in turn.

(i) The agent requests in line 16: "Please discuss what you predict will happen in these two conditions." Student S034 complies after a lengthy two-and-a-half minutes of silence by asking the group, "what do you think'ds going to happen?" At this point, the agent interjects some information about a third condition and asks the students to move on to discussing that. The timing of this seems questionable if the goal is to encourage extended knowledge-building interaction among the students. Student S041 then ignores the agent's latest contribution and responds ironically to student S034's request for a prediction: "the world is going to end in 2012."

(ii) The agent quickly picks up on S041's prediction by introducing the indirect prompting for accountable talk in line 23: "S027, now would be a good time to ask S034 to build on what S041 is saying." This all confuses S034, who states, "im so confused!" But S027 dutifully instructs S034 to explain S041's remark by building on it and explaining it to S027: "034, would you like to build on to what 041 is saying? and me too!" The first part of this follows the script prompted by the agent, but S027 adds his sympathetic addendum, aligning with S034 by agreeing that he is also confused about what is being asked of them.

(iii) The final mediation is similar to the first. In line 26, the agent requests: "When you are in agreement, write down your predictions and explanations for Conditions A, B and C on your worksheet." A minute later, after S027 complains again of not knowing what to do, S034 says, "someone predict something." Student S041 responds again to student 034: "THE WORLD IS GOING TO END IN 2012!"

As the green arrows indicate, almost all uptake of content is associated with these three mediated interactions. Line 8 merely introduces the student, repeating the word "name": S034 responds to the agent's "I didn't get your names yet" with "my name is \{S034\}." Line 107 responds to line 105's birthday greeting with "is it ur birthday?" These are not knowledge-building moves, but are social interactions, not directly relevant to accountable talk about curricular content.

There is some evidence that the agent is responding to student postings. The agent's line 7 succeeds in getting S034 to give his or her name and the agent then responds to that by assigning a role to S034. At line 23, the agent responds to a posting by S041 by asking S027 to ask S034 to build on what S041 said. This is an instance of the indirect mediation. While the timing is appropriate to ask S027 and S034 to discuss a posting by S041, the agent clearly fails to understand the significance of the posting. The agent assumes that S041 has made a prediction about the biology experiment, and not a sarcastic joke. This could have sent the group off on a distracting tangent, but in fact only confused the students about the agent's behavior and the meaning of the agent's requests.

If we look at the blue arrows in Figure 1, we see that the only times that the agent responded to the students were in lines 9 and 23. In line 9, the agent started to assign roles that were ignored by the students. In line 23 , the agent requested an accountable-talk script to build on a joke.

A look at the high-level visual structure for Figure 1 indicates that the agent dominated the discussion in the early part, but then was ignored for most of the remainder of the chat. Toward the end, there was a significant pattern of interaction among the students, who seemed to be engaged as a group. A closer look 
at the content of the individual students' postings suggests that S034 is trying hard to accomplish the class task. S027 seems generally lost. S041 is not interested in the biology and is more oriented to clowning around. There is no apparent correlation of their individual behaviors to the roles assigned to them by the agent.

The period from posting 5 through 18 lasted about four minutes. This period is totally dominated by the agent, which posted over 260 words while the three students responded with a total of 9 words, mostly just stating their names. The agent did not acknowledge their responses or appear to respond to them, except as noted above. Although delivering instructions to the students through the agent may have been motivated by an attempt to establish dialog between the agent and the students, it positioned the agent as an authoritative source of knowledge and commands, while positioning the group of students as a set of largely passive listeners, thus discouraging student discursive agency.

Of course, it made no sense for the agent to ask the students to "build on" to the sarcastic answer in line 22. This response by $\mathrm{S} 041$ shows that he/she already did not take the agent seriously. By not interacting with the students in a way that makes sense to them, the agent fails to establish itself as a serious participant in the group discourse. Caught in the middle between human interaction with the other students and obeying the authoritative orders of the agent, S027 follows the agent's command, but adds his protest against the agent's leadership in line 25.

S027 and the other students then stop orienting to the agent and the agent is ignored for the next 10 minutes until it again provides an unhelpful indirect prompt for accountable talk at line 69. Instead of responding to the agent prompt, S027 asks who is 34 and says "ooh. hi" when S034 responds. The students go on to work together to fill in the worksheet. One student provides the answers and the others try to figure out how to copy those answers into their own worksheets.

The agent continues to give commands, but they are generally ignored. When in line 69 the agent prompts once more for accountable talk, the students agree that the agent is being an insufferable nuisance. They evaluate the whole supported chat experience by agreeing that "this would be so much easier just in a group," meaning just sitting together without any computer or agent support and filling in their worksheets. Their only subsequent response to the agent is to celebrate when it leaves.

\section{Discussion: Issues Observed}

In the experiment, students were placed in small groups of three students and an agent in a chat room. This is a setting that calls for intense text-based interaction. The patterns in Figure 1 are already visually suggestive. The agent does not significantly respond to (i.e., interact with) students. The student responses to the agent are problematic. After trying to be responsive, the students give up and start to engage in their own discussion. Periods of their interaction show considerable back-and-forth responses as they elicit responses, provide responses, and then acknowledge the responses to each other in various ways. Student responses are tightly situated in the on-going discourse, whereas the agent speaks like an academic textbook, with no sense of contextualization and little apparent attempt at interaction.

The educational experiment is an attempt to support collaborative learning with (a) the VMT software environment, (b) software helping agents (c) a social small-group setting, and (d) accountable-talk prompts. It is a CSCL intervention that aims to scaffold collaborative learning with these forms of computer support and communication structuring.

(a) The first problem is that the lesson design does not succeed in fostering collaboration. The students are each given their own worksheet to fill out and then they are each tested individually. There is no meaningful group task or group goal to be accomplished collaboratively. The questions to be addressed by the students are not open-ended issues to encourage group inquiry and discussion, but questions with instructor-defined correct answers that the students can solve individually. Consequently, there is little evidence of real knowledge building taking place collaboratively. The most that occurs is that a student 
who knows the correct answer will give it to students who do not know it. Rather than this taking place as accountable talk, it naturally takes place in the form of students copying each other's answers to fill in their individual forms, without caring much about understanding the science-i.e., a common school process understood by all as cheating rather than collaborating or learning. The VMT environment was designed for shared tasks, with a shared whiteboard provided as a shared external memory that can be even more important for communication and joint work than the text chat (Çakır, Zemel \& Stahl, 2009). Rather than this, the experiment uses the whiteboard to display once more a static cartoon of accountable talk, which appears to have been completely ignored by the students. The whiteboard could have contained the worksheet, to be filled out collaboratively by the team. That group artifact could then have been evaluated for the grading, rather than threatening the students with individual quizzes (causing expressions of test phobia). The shared whiteboard (or additional tabs with web browsers or other whiteboards) could also have been used to present data of the biology experiment, rather than having the students have to start up other applications (causing further confusion).

(b) The second problem involves the design of the agent interventions. First of all, the agent was in effect non-interactive. The agent may have been carefully programmed to intervene in an interactive way, but it does not come off that way in a sequential analysis of the chat-which is more important than the intentions of the programmer. To the students, the agent's timing did not appear to be effectively coordinated with the student discourse or responses. Inevitably, the agent postings introduced confusion for the students rather than clear structure. They were incredibly verbose-within the chat medium, which is known for its conciseness of expression. It might have made more sense to explain the process in class before breaking into online chat groups. Helping agents should probably not be used to automate teachercentric instructors, but should get out of the way of student interaction until the students express a need for help. When an agent does intervene, it has to know what is going on well enough to judge what kind of response might be helpful. The agent behavior programmed here was an extreme example of "over scripting" and the opposite of the recommended "SWISH approach" (Dillenbourg, 2002; Dillenbourg \& Jermann, 2006).

(c) A third problem involves social identity. Teenage students are mainly learning social skills, despite teacher efforts to have them learn curricular content. So when they are put together to interact in small groups it is essential to them that they know as much as possible about each other. In the VMT Project, we tried to put together students with no prior knowledge of each other so that we researchers could know everything the students knew about each other, so that we could interpret their interaction logs on a par with their understanding of the group interaction. In this biology case study, the students knew each other very well and had well practiced relationships. By assigning the chat participants anonymous identifiers, the experiment interfered with their exercise of these important and motivating social relationships (see chapter by Cress \& Kimmerle, this volume). The students spent much time and attention in overcoming this circumstance (e.g., chat lines 17/18 and 27/28/30), positioning them in opposition to the conditions imposed upon their daily routines by this experimental intervention.

(d) Finally, accountable talk needs to take place at a sophisticated level of discourse. Like all effective discourse, it must be highly situated in the on-going discussion. That is the skill of a teacher who has mastered accountable talk moves, to know just when and how to prompt. A complicated prompt cannot just appear out of the blue and hope to be helpful in building shared understanding. This poses a major technical challenge for software agents at many levels; it will require many cycles of design-based research to evolve an effective interaction behavior for helping agents that can effectively prompt for accountable talk by students.

\section{Conclusions: Suggestions for Redesign}

The biology experiment is cutting-edge research. The components that it brings together each require groundbreaking advances in the knowledge of their domain. It is not a matter of simply applying wellunderstood techniques. 
(a) It took years of research by a large international, interdisciplinary team to develop the integration of pedagogy, problem, and technology for the Virtual Math Teams Project in the domain of collaborative online discourse of school mathematics - and there is still much investigation to be done there. Similar explorations will be needed for the domain of online discourse of school biology. A primary issue in guiding student inquiry in small online groups is how to avoid intruding in the important processes of small-group collaboration among the students; the case study just analyzed shows that there is a long way to go in achieving this with the approach tried. Our past research emphasizes how important yet difficult guidance or scaffolding of collaborative knowledge building is to achieve. In the VMT Project, we often had an adult facilitator in the chat room with the group of students. We trained the facilitators to avoid intervening too much in the interaction, mainly answering questions and helping with technology issues. A study of this showed the subtlety of supporting student group agency rather than interfering with it (Charles \& Shumar, 2009).

(b) Involving software agents as participants in open-ended collaboration is quite different from the approaches that have been so successful in automated tutors of individual students being trained in welldefined algebra procedures within tightly constrained interfaces. In collaboration with Carolyn Rosè's research group, we started to explore the interaction of software agents with students in online discussions in the VMT environment with experiments in a mathematics classroom (Stahl et al., 2010). Here we discovered how invasive agents tend to be. Even with "wizard of Oz" experiments in which human researchers played the role of software agents, the presence of the "agents" radically transformed the online interaction. The students oriented their discussion to the agents instead of to each other and to the math problems. Much more experimentation seems necessary to design less invasive agent behaviors, even in theory. In addition, it may be necessary to study successful examples of accountable-talk prompts or interventions by skilled teachers, using the micro-analytic techniques of conversation analysis before trying to design software algorithms to replicate such expert behavior. In particular, we need to know how to effectively time interventions and how to adapt the linguistic structure of interventions to the on-going discourse.

(c) Designing effective CSCL interventions and introducing new technologies to scaffold interaction is a complex undertaking. It requires many cycles of iteration. The data analyzed here functions as an initial, pilot iteration. It was probably premature to run multiple conditions and to expect to see effects in subsequent testing of individual students. If anything, the VMT environment, the software agents, and the accountable-talk prompts seem to have each done more to interfere with any possibility of collaborative discussion of biology than to promote it.

(d) The theory of accountable talk has intuitive appeal to scientifically well-trained, mature, rational adults, whose thinking is heavily influenced by explicit textual expression. However, theories relevant to CSCL stress the social, situated, and linguistic nature of cognition (Stahl, 2011b). To introduce accountable-talk moves into the highly situated, socially interactive text-chat interaction of school children will involve much more than providing canned prompts of the form used in the case study. It will require understanding the situated, sequential, social, interactional character of student chat, developing agents that can follow these subtle processes through real-time analysis of cryptic, ironic, juvenile postings and can formulate agent postings that engage in the co-construction of shared understanding. It is even possible that actually accomplishing that would exceed the theoretical possibilities of artificial intelligence to engage in intersubjectivity with humans. But before we can reasonably speculate on that, it seems important to understand the nature of effective knowledge-building discourse and productive accountable talk prompting; again, micro analysis of prototypical examples of such interaction need to be carried out.

The point now is to take the lessons learned back to the drawing board for extensive redesign: (a) First, integrate more aspects of the experiment into the collaboration-support software environment by allowing the group to see the experiment results in a shared view and to embed its inquiry reasoning and its scientific conclusions in the VMT shared whiteboard. This can make better use of the collaboration tools 
of the software as a collaborative medium. (b) Second, develop the agents to follow the student discourse and to just intervene when needed. This involves real-time natural language processing of the student postings, which is a complex, subtle, and situated skill, which may exceed the current state of the art. (c) Third, encourage collaboration among friends by letting the students know each other's identities and having them work for a group product, rather than the filling in individual worksheets and taking individual tests. This would transform the exercise from one focused on individual learning to collaborative knowledge building. (d) Fourth, figure out how accountable-talk prompts can be contextualized as part of natural verbal interaction. This will involve development of this approach beyond the current conceptualization of the technique.

Methodologically, this stage of research calls for observations of pilot studies in order to guide design in the various aspects of the project. A single case study, looking in detail at the interactions, can provide insight into what group processes take place empirically-in ways that quantitative comparisons of different conditions generally cannot. This can provide important contrasts to what designers assumed would take place based on their best preconceptions. Statistical controlled comparisons and quantitative measures of changes in individual test results at this stage would likely produce results that would at best be confusing, but more likely be misleading when interpreted on the basis of researcher preconceptions of what transpires in student interaction. This paper has tried to provide a detailed case study that analyzes the response structure of actual interaction (among humans and agents) to reveal processes that are fundamental to human interaction under such conditions and are therefore likely to take place in other cases. It has tried to show how interaction analysis focused on the response structure of interaction can provide insight into group-cognitive processes and can indicate how experimental interventions do or do not support the group interaction. Hopefully, this paper can contribute to guiding design-based research at this early stage of educational design.

\section{References}

Çakır, M. P., Zemel, A., \& Stahl, G. (2009). The joint organization of interaction within a multimodal CSCL medium. International Journal of Computer-Supported Collaborative Learning. 4(2), 115 149. Web: http://GerryStahl.net/pub/ijCSCL 42 2 1.pdf

Charles, E. S., \& Shumar, W. (2009). Student and team agency in VMT. In G. Stahl (Ed.), Studying virtual math teams. (ch. 11, pp. 207-224). New York, NY: Springer. Web: http://GerryStahl.net/vmt/book/11.pdf

Dillenbourg, P. (2002). Over-scripting CSCL: The risks of blending collaborative learning with instructional design. In P. Kirschner (Ed.), Three worlds of CSCL: Can we support CSCL? (pp. 6191). Heerlen, Netherlands: Open University of the Netherlands.

Dillenbourg, P., \& Jermann, P. (2006). Designing integrative scripts. In F. Fischer, H. Mandl, J. Haake \& I. Kollar (Eds.), Scripting computer-supported collaborative learning: Cognitive, computational and educational perspectives. (pp. 275-301). Dodrecht, Netherlands: Kluwer-Springer Verlag.

Jordan, B., \& Henderson, A. (1995). Interaction analysis: Foundations and practice. Journal of the Learning Sciences. 4(1), 39-103. Web: http://lrs.ed.uiuc.edu/students/c-merkel/document4.HTM

Resnick, L., O'Connor, C., \& Michaels, S. (2007). Classroom discourse, mathematical rigor, and student reasoning: An accountable talk literature review.

Sacks, H. (1962/1995). Lectures on conversation. Oxford, UK: Blackwell.

Schegloff, E. A. (2007). Sequence organization in interaction: A primer in conversation analysis. Cambridge, UK: Cambridge University Press.

Stahl, G. (2006). Sustaining group cognition in a math chat environment. Research and Practice in Technology Enhanced Learning (RPTEL). 1(2), 85-113. Web: http://GerryStahl.net/pub/rptel.pdf

Stahl, G. (2009). Studying virtual math teams. New York, NY: Springer. 626 +xxi pages. Web: http://GerryStahl.net/vmt/book

Stahl, G. (2011a). The structure of collaborative problem solving in a virtual math team. Paper presented at the iConference 2011. Seattle, WA. Web: http://GerryStahl.net/pub/iconf2011.pdf 
Stahl, G. (2011b). Theories of cognition in collaborative learning. In C. Hmelo-Silver, A. O'Donnell, C. Chan \& C. Chinn (Eds.), International handbook of collaborative learning. New York, NY: Taylor \& Francis. Web: http://GerryStahl.net/pub/clhandbook.pdf

Stahl, G., Rosé, C. P., O'Hara, K., \& Powell, A. B. (2010). Supporting group math cognition in virtual math teams with software conversational agents. Paper presented at the First North American GeoGebra Conference. Ithaca, NY. Web: http://GerryStahl.net/pub/geogebrana2010a.pdf

Appendix: The Chat Log

\begin{tabular}{|c|c|c|c|c|c|}
\hline & time & Tutor & $\underline{\mathrm{S027}}$ & $\underline{\mathrm{S034}}$ & $\underline{S 041}$ \\
\hline 1 & 11.54 .45 & & & & \\
\hline 2 & 11.55 .35 & & & & \\
\hline 3 & 11.55 .41 & & & & \\
\hline 4 & 11.55 .51 & & & & \\
\hline 5 & 11.56 .01 & $\begin{array}{l}\text { Hi all! Today, each of you will be both the instructor and the } \\
\text { student. Each of you will be responsible for looking for } \\
\text { opportunities for a specific discussion strategy to be used in } \\
\text { the conversation. }\end{array}$ & & & \\
\hline 6 & 11.56 .06 & Lets get started by introducing ourselves. I am Alex. & & & \\
\hline 7 & 11.57 .04 & S034,S041,S027... i didn't get your names yet. & & & \\
\hline 8 & 11.57 .16 & & & my name is $\{\mathrm{SO} 34\}$ & \\
\hline 9 & 11.57 .16 & $\begin{array}{l}\text { Hi S034 you are the Revoicer. When an explanation or idea } \\
\text { is given which would benefit from revoicing, please } \\
\text { encourage one of your team mates to do so, for example, } \\
\text { by asking them to explain what was said in their own words. }\end{array}$ & & & \\
\hline 10 & 11.57 .24 & $\begin{array}{l}\text { S041, you are the Challenger. When you see a statement } \\
\text { being made (whether it is right or wrong) which would } \\
\text { benefit from being challenged, please encourage one of } \\
\text { your team mates to do so, for example, by asking them } \\
\text { whether they agree or disagree with what was said, and } \\
\text { why. }\end{array}$ & & & \\
\hline 11 & 11.57 .25 & & & & $\{\mathrm{~S} 041\}$ \\
\hline 12 & 11.57 .31 & $\begin{array}{l}\text { Ok... So the Explainer is S027. When you see a place where } \\
\text { it would be good to get more explanation, you can } \\
\text { encourage one of your team mates to do that, for example, } \\
\text { by inviting that person to add on to what the other student } \\
\text { has already said. }\end{array}$ & & & \\
\hline 13 & 11.57 .37 & $\begin{array}{l}\text { You should probably all mark an X opposite your role in the } \\
\text { book, so you won't forget. }\end{array}$ & & & \\
\hline 14 & 11.57 .43 & $\begin{array}{l}\text { Its nice to meet you all. :) Please make sure you have } \\
\text { understood what you are responsible for. }\end{array}$ & & & \\
\hline 15 & 11.58 .00 & $\begin{array}{l}\text { In condition A, we placed a glucose solution inside the cell } \\
\text { model and immerse it in distilled water. In condition B, we } \\
\text { did the opposite. }\end{array}$ & & & \\
\hline 16 & 11.58 .05 & $\begin{array}{l}\text { Please discuss what you predict will happen in these two } \\
\text { conditions. }\end{array}$ & & & \\
\hline 17 & 11.59 .29 & & & & who is 27 \\
\hline 18 & 12.00 .06 & & $\{\mathrm{~S} 027\}$ & & \\
\hline 19 & 12.00 .46 & & & $\begin{array}{l}\text { what do you think'ds going to } \\
\text { happen? }\end{array}$ & \\
\hline
\end{tabular}




\begin{tabular}{|c|c|c|c|c|c|}
\hline 20 & 12.01 .02 & $\begin{array}{l}\text { In condition C, we made a modification to condition A. We } \\
\text { replace the glucose solution with a starch suspension. In } \\
\text { order to detect the presence of starch, we replace the } \\
\text { distilled water with Lugol's lodine solution. }\end{array}$ & & & \\
\hline 21 & 12.01 .07 & $\begin{array}{l}\text { You should now move on to discussing what will happen in } \\
\text { Condition C and your explanation for this change. }\end{array}$ & & & \\
\hline 22 & 12.01 .14 & & & & $\begin{array}{l}\text { the world is going } \\
\text { to end in } 2012\end{array}$ \\
\hline 23 & 12.01 .21 & $\begin{array}{l}\text { S027, now would be a good time to ask S034 to build on } \\
\text { what S041 is saying. }\end{array}$ & & & \\
\hline 24 & 12.02 .00 & & & im so confused! & \\
\hline 25 & 12.02 .08 & & $\begin{array}{l}\text { 034, would you like to } \\
\text { build on to what } 041 \text { is } \\
\text { saying? and me too! }\end{array}$ & & \\
\hline 26 & 12.02 .32 & $\begin{array}{l}\text { When you are in agreement, write down your predictions } \\
\text { and explanations for Conditions A, B and C on your } \\
\text { worksheet. }\end{array}$ & & & \\
\hline 27 & 12.02 .42 & & who is $34 ?$ & & \\
\hline 28 & 12.02 .53 & & & $\{\mathrm{~S} 034\}$ & \\
\hline 29 & 12.03 .00 & $\begin{array}{l}\text { You are now going to watch a video showing the cell in } \\
\text { Conditions A, B and C. }\end{array}$ & & & \\
\hline 30 & 12.03 .04 & & ooh. hi & & \\
\hline 31 & 12.03 .05 & $\begin{array}{l}\text { As you watch the video, write down your observations on } \\
\text { your worksheet. }\end{array}$ & & & \\
\hline 32 & 12.03 .11 & $\begin{array}{l}\text { Go to the Videos folder on the Desktop, and watch the video } \\
\text { which is there. }\end{array}$ & & & \\
\hline 33 & 12.03 .24 & & idk what to do. & & \\
\hline 34 & 12.03 .27 & & & someone predict something & \\
\hline 35 & 12.03 .56 & & & & $\begin{array}{l}\text { THE WORLD IS } \\
\text { GOING TO END IN } \\
2012 !\end{array}$ \\
\hline 36 & 12.04 .05 & & & $\begin{array}{l}\text { oh i get it! what do you think is } \\
\text { going to happen when you put } \\
\text { the glucose in the distilled water? }\end{array}$ & \\
\hline 37 & 12.04 .22 & & $\begin{array}{l}\text { i think it will turn a } \\
\text { different color. }\end{array}$ & & \\
\hline 38 & 12.04 .29 & & $\{\mathrm{~S} 041\} ?$ & & \\
\hline 39 & 12.04 .45 & & & & $\begin{array}{l}\text { ok dude what } 27 \\
\text { said }\end{array}$ \\
\hline 40 & 12.05 .04 & & in your own words & & \\
\hline 41 & 12.05 .10 & & ?!?!?! & & \\
\hline 42 & 12.05 .26 & & & & $\begin{array}{l}\text { you have to be } \\
\text { more specific } 27\end{array}$ \\
\hline 43 & 12.05 .43 & & ur one to talk!!! & & \\
\hline 44 & 12.05 .46 & & & $\begin{array}{l}\text { the answer to number one : the } \\
\text { distilled water will move into the } \\
\text { internal envorment of glucose } \\
\text { solution }\end{array}$ & \\
\hline 45 & 12.06 .36 & & $\mathrm{kk}$ & & \\
\hline 46 & 12.06 .45 & & & $\begin{array}{l}\text { and the explaination is glucose is } \\
\text { denser }\end{array}$ & \\
\hline 47 & 12.06 .57 & & & & huh? \\
\hline
\end{tabular}




\begin{tabular}{|c|c|c|c|c|c|}
\hline 48 & 12.07 .05 & & $\begin{array}{l}\text { just write what } \\
\text { she }[\{S 034\}] \text { said. }\end{array}$ & & \\
\hline 49 & 12.07 .20 & & & & for the explination \\
\hline 50 & 12.07 .33 & & & $\begin{array}{l}\text { \#2 the distilled water will move } \\
\text { into the external enviroment }\end{array}$ & \\
\hline 51 & 12.08 .14 & & & watch the video & \\
\hline 52 & 12.08 .38 & Is everyone back? & & & \\
\hline 53 & 12.08 .45 & & & & $\begin{array}{l}\text { we have to do all } \\
\text { the prediction, } \\
\text { thats what NACHO } \\
\text { said }\end{array}$ \\
\hline 54 & 12.08 .48 & & $\begin{array}{l}\text { ok, but where do i click } \\
\text { to watch it? }\end{array}$ & & \\
\hline 55 & 12.09 .00 & $\begin{array}{l}\text { Now discuss what you observed in the video about } \\
\text { conditions A and B. Compare what you observed to your } \\
\text { predictions. }\end{array}$ & & & \\
\hline 56 & 12.09 .40 & & nevermind i found it. & & \\
\hline 57 & 12.10 .01 & & & $\begin{array}{l}\text { \#3 the water will move into the } \\
\text { starch because starch absorbs it }\end{array}$ & \\
\hline 58 & 12.10 .08 & $\begin{array}{l}\text { S027, now would be a good time to ask S041 to build on } \\
\text { what S034 is saying. }\end{array}$ & & & \\
\hline 59 & 12.10 .33 & & $\begin{array}{l}\{\mathrm{SO34}\} \text { are these \#'s } \\
\text { all of the predictions or } \\
\text { explanations? }\end{array}$ & & \\
\hline 60 & 12.11 .51 & & $\{$ S034\}? & & \\
\hline 61 & 12.12 .01 & & & yeaaaa & \\
\hline 62 & 12.12 .02 & $\begin{array}{l}\text { You should now move on to discussing what you observed } \\
\text { in the video about condition C. Compare what you observed } \\
\text { to your predictions. How is this different from what } \\
\text { happened in condition A? }\end{array}$ & & & \\
\hline 63 & 12.12 .25 & & $\begin{array}{l}\# 3 \text {, is that the } \\
\text { prediction? }\end{array}$ & & \\
\hline 64 & 12.12 .41 & $\begin{array}{l}\text { Lets spend the rest of the time we have discussing your } \\
\text { observations from all the three conditions. }\end{array}$ & & & \\
\hline 65 & 12.12 .47 & $\begin{array}{l}\text { Discuss explanations of what you observed in each condition } \\
\text { and make sure you fill in your explanations on your } \\
\text { worksheets. }\end{array}$ & & & \\
\hline 66 & 12.13 .00 & & & & $\begin{array}{l}\text { what is } \\
\text { explanation for } \\
\# 2\end{array}$ \\
\hline 67 & 12.13 .07 & & idk. & & \\
\hline 68 & 12.13.07 & & & $\begin{array}{l}\text { its both, the first part is the } \\
\text { prediction the second part is the } \\
\text { explanation }\end{array}$ & \\
\hline 69 & 12.13 .13 & @S027, can you ask S041 to build on what S034 is saying. & & & \\
\hline 70 & 12.13 .34 & & & $\begin{array}{l}\text { i want to shoot myself in the foot } \\
-\because-\end{array}$ & \\
\hline 71 & 12.13 .50 & & ikr. & & \\
\hline 72 & 12.14 .00 & & this is so stupid. & & \\
\hline 73 & 12.14 .11 & & & $\begin{array}{l}\text { this would be so much easier just } \\
\text { in a group }\end{array}$ & \\
\hline
\end{tabular}




\begin{tabular}{|c|c|c|c|c|c|}
\hline 74 & 12.14 .19 & & уер уер & & \\
\hline 75 & 12.14 .23 & @S027, can you ask S041 to build on what S034 is saying. & & & \\
\hline 76 & 12.14 .25 & & & & $\begin{array}{l}\text { you dont have the } \\
\text { balls to do it }\end{array}$ \\
\hline 77 & 12.14 .36 & & & & \\
\hline 78 & 12.14 .38 & Ok, I gotta go. & & & \\
\hline 79 & 12.14 .43 & It was nice talking to you all. :-) & & & \\
\hline 80 & 12.14 .55 & & our tutor left us!!! & & \\
\hline 81 & 12.15 .10 & & & $\mathrm{D}:$ & \\
\hline 82 & 12.15 .23 & & she is a baad tutor!!! & & \\
\hline 83 & 12.15 .44 & & & im pretty sure its a he & \\
\hline 84 & 12.16 .09 & & $\begin{array}{l}\text { really? haah! oh well. } \\
\text { idc. he/she/it }\end{array}$ & & \\
\hline 85 & 12.16 .31 & & $\begin{array}{l}\text { i ddnt even watch the } \\
\text { whole video }\end{array}$ & & \\
\hline 86 & 12.16 .49 & & & i watched most of it & \\
\hline 87 & 12.16 .58 & & $\begin{array}{l}\text { do you know what } \\
\text { happened? }\end{array}$ & & \\
\hline 88 & 12.17 .13 & & & i just wrote the observations & \\
\hline 89 & 12.17 .42 & & $\begin{array}{l}\text { oh. what was it after } 1 \\
\text { hour for condition A? }\end{array}$ & & \\
\hline 90 & 12.19 .17 & & $\begin{array}{l}\text { \{S041\}, did you get } \\
\text { everything so far? }\end{array}$ & & \\
\hline 91 & 12.19 .24 & & & $\begin{array}{l}\text { condition a: } 620 \text { glucose inside; } \\
635 \text { glucose inside; } 630 \text { glucose } \\
\text { inside; explanation: the } \\
\text { membrane will hold stuff for a } \\
\text { certain amount of time }\end{array}$ & \\
\hline 92 & 12.20 .05 & & & $\begin{array}{l}\text { condition b: } 540 \text { glucose outside; } \\
525 \text { glucose outside; } 525 \\
\text { glucose outside; explanation: the } \\
\text { glucose was not being absorbed } \\
\text { by the water }\end{array}$ & \\
\hline 93 & 12.20 .10 & & & i think. & \\
\hline 94 & 12.21 .45 & & $\begin{array}{l}\text { k, i'll fast forward and } \\
\text { try to find the last one, } \\
\text { when im done writing } \\
\text { the condition b. }\end{array}$ & & \\
\hline 95 & 12.21 .47 & & & & you mean i know! \\
\hline 96 & 12.22 .02 & & & $\begin{array}{l}\text { yea, sure i do, whatever. } \\
\text { hahahahahha }\end{array}$ & \\
\hline 97 & 12.22 .15 & & lol & & \\
\hline 98 & 12.22 .19 & & & & lol what is $\mathrm{C}$ \\
\hline 99 & 12.22 .27 & & & i dont even think there was one & \\
\hline 100 & 12.22 .33 & & $\begin{array}{l}\text { i sd i'd try to find it if i } \\
\text { could. }\end{array}$ & & \\
\hline 101 & 12.22 .51 & & & & there is $\&$ ok \\
\hline
\end{tabular}




\begin{tabular}{|c|c|c|c|c|}
\hline 102 & 12.23 .04 & $\begin{array}{l}\text { aaah there is a } \\
\text { quiz!!!!!!!!!!!!! }\end{array}$ & & \\
\hline 103 & 12.23 .19 & im gonna fail!!!!!!!!!!!!! & & \\
\hline 104 & 12.23 .57 & & & stfu! \\
\hline 105 & 12.23 .59 & & $\begin{array}{l}\text { HAPPY BIRTHDAAAY }\{S 041\}: D \\
: D: D: D: D: D: D: D: D\end{array}$ & \\
\hline 106 & 12.24 .10 & & & lol thsnks \\
\hline 107 & 12.24 .13 & is it ur birthday? & & \\
\hline 108 & 12.24 .20 & & [blank line] & \\
\hline 109 & 12.24 .23 & & [blank line] & \\
\hline 110 & 12.24 .23 & & [blank line] & \\
\hline 111 & 12.24 .23 & & [blank line] & \\
\hline 112 & 12.24 .23 & & [blank line] & \\
\hline 113 & 12.24 .23 & & [blank line] & \\
\hline 114 & 12.24 .24 & $\ldots$ & & \\
\hline 115 & 12.24 .25 & & & \\
\hline 116 & 12.24 .35 & bye bye guys. & & \\
\hline 117 & 12.25 .01 & & & \\
\hline 118 & 12.25 .11 & & & \\
\hline 119 & 12.28 .34 & & & \\
\hline
\end{tabular}

